\title{
THE RELATIONSHIP BETWEEN CORE STABILITY PERFORMANCEAND THE LOWER EXTREMITIES STATIC BALANCE PERFORMANCE IN RECREATIONALLYACTIVE INDIVIDUALS
}

\author{
Journal website at; \\ http://mrtbjournal.org/index.php/njmr/issue/current/showToc
}

\begin{abstract}
ANOOP AGGARWAL,SURAJ KUMAR, ZUTSHI KALPANA, MUNJALJITENDER, V PSHARMA
Department of Physiotherapy, Pt.DDU IPH, New Delhi-110002, India.
\end{abstract}

\author{
Correspondence to: \\ AnoopAggarwal \\ Department of physiotherapy Institute for physically handicapped \\ (Ministry of Social Justice and Empowerment) \\ Delhi, India \\ - anoop_bpt@yahoo.com, surajdr2001@yahoo.com \\ Mobile No. - +91-9911261730, +91-9968008415
}

\section{SUMMARY}

Background: Lumbar core stability performance may be a function of the core muscles of the lumbar spine. Lumbar spine dysfunction could be related with the lower extremity functional performance including balance performance.

Objective: The present study was undertaken to determine the correlation between the Core stability performance and the lower extremity static balance performance in the recreationally active individuals. Establishing a relation between the core stability and balance performance will provide a rationale to give core stability training for reducing balance deficit related injuries.

Methods: Forty recreationally active subjects (20 males and 20 females) were selected for this study on the basis of inclusion and exclusion criteria. Their Core stability performance was evaluated using PBU Sorenson test and the lower extremity static balance performance using the Stork single limb balance test. Data was analyzed using the Spearman rank correlation and Pearson correlation test.

Results: balance performance was significantly correlated with that of the Sorensen test, PP (prone plank) test and PBU test but not with RP (right plank), LP (left side plank) and $\mathrm{AF}$ (abdominal fatigue test) performance.

Conclusion: This study concludes that there is significant correlation of the lower extremity balance performance with that of the core stability in sagital plane.
KEYWORDS: Core stability, Balance, Stork balance test

\section{INTRODUCTION}

Outdoor sports and recreational sports participation is increasing at faster pace among adolescents. Consequently, along with an increase in the frequency or duration of recreational sports participation, there is a proportional increase in the incidence of activity induced musculo-skeletal injury which acts as a true public health burden (Haapasalo et al 2007). Patrick and Carl (2008) documented that ankle sprains are among the most common injuries in the physically active population. It is estimated that 23,000 ankle sprains occur daily in the United States. It has been estimated that sprains to the ankle/foot account for 1.6 million physician office visits and over 8000 hospitalizations per year. Approximately $30 \%$ of those who suffer a first-time ankle sprain develop chronic ankle instability (CAI); however this rate has been reported as high as $70 \%$. Residual symptoms of ankle sprain force them to become less active over the life span (Patrick et al 2008). Mcguine and Keene (2006) found that unilateral balance (using posture sway measure), is a significant predictor of susceptibility of ankle to injury in basketball high school players. They found that subjects with good balance score (thus low postural sway) have nearly 7 times reduced risk of ankle sprain in comparison to people with poor balance (high postural sway). Various training programs have been used in past to train ankle muscles for improved balance ability.

Recently fitness training \& injury prevention programs that incorporate spinal musculature training, 
including core strengthening and stability exercises have become popular because the core is considered to be the anatomic and functional centerpiece (Bliss \& Teeple 2005) and the powerhouse of the body. In essence, the "core" can be viewed as a box with the abdominals in the front, paraspinals and gluteals in the back, the diaphragm as the roof, and the pelvic floor and hip girdle musculature as the bottom. Within this box are 29 pairs of muscles that help to stabilize the spine, pelvis, and kinetic chain during functional movements. When the system works efficiently, the result is appropriate distribution of forces; optimal control and efficiency of movement; adequate absorption of ground-impact forces; and an absence of excessive compressive, translation, or shearing forces on the joints of the kinetic chain (Alexis et al, 2006).

All motions are generated from the core and are translated to the extremities (Bliss \& Teeple 2005). During performance of sports skills, a stable core provides a foundation upon which the muscles of the upper and lower extremities can accelerate body segments and transfer force between distal and proximal body segments (Hodge \& Richardson 1997; Willardson 2007).

Balance is a complex motor skill that describes the dynamics of body posture to prevent falls. Balance is related to the inertial forces acting on the body and the inertial characteristics of body segments. Balance control can be examined from neuro-physiological, biomechanical and functional perspectives depending on the goal of the study. Biomechanically balance can be defined as the ability to maintain or return the body's COG (center of gravity) within the limits of LOS (limit of stability) as determined by BOS (base of support) (Anne P, 2005). Static balance is the ability to maintain Center of gravity (COG) within BOS (base of support). It aims to keep the center of pressure (COP) of body as immobile as possible within the BOS during standing or sitting (Anne P, 2005). It is a well known fact that the position of body's COG is significantly influenced by the positions of inter-vertebral segments. Also the higher core stabilization ability is responsible for more optimum control of the vertebral segments. Thus we hypothesize that there should possibly a correlation between core stabilization performance and the static balance ability.

A variety of tests such as abdominal fatigue test (Alexis et al, 2006;Willson et al, 2005), Biering Sorensen test (Alexis et al, 2006; Darin and Mary, 2004), double leg lowering test (David et al, 2005), prone plank stability test (prone bridges) (Alexis et al, 2006), side plank bridging tests (Willson et al, 2005) are now used as the tool of measurement of the core stabilization (without requiring any sophisticated instruments) by large number of authors. The stabilizer Pressure Biofeedback Unite (PBU) directly assesses the ability of the abdominal muscles to actively stabilize the lumbar spine (Richardson et al 1993). This instrument represents a bold first attempt to assess LPS and, although a gold standard does not exist with which to quantify its validity, it is frequently used to direct clinical decision-making in regards to LPS impairment (Mills et al, 2005; Richardson et al 1993).

Previous study (Bohdanna et al 2007) has reported that sports participants having higher core stability performance also show higher performance of lower extremity however the relation between core stability performance and the lower extremity balance performance has not been reported in a quantitative fashion till date conclusively. The aim of this present study was to determine the correlation among different tests of core stability and the static balance performance. Correlation will provide an evidence of direct linkage between core stability performance and static balance performance.

\section{MATERIALSAND METHODS Subjects}

Forty recreationally active, individuals (20 males, 20 females), without any known neuromuscular, orthopedic, or cardiovascular conditions, were recruited for the study. Subjects were recruited from those who voluntarily reported at the physiotherapy department of the Majeedia Hospital and exercise therapy laboratory of the university. All participants were recreationally active players who participated in the outdoor sports activity at least 20 minutes a day for three days per week. All the participants were excluded if they had low back pain during last six months or history of surgery or participation in any training program for the core stability training, strength training, resistance training or balance training.

The potential volunteered candidates were explained nature and purpose of the study and those who agreed to participate were given the screening questionnaire to judge their suitability for the study. Those who did not meet the inclusion criteria of the study were screened out. After advertisement 153 subjects volunteered for participation in the study only 91 subjects met inclusion criteria and were divided into male group and female group. Male group had 55 subjects and female group had 36 subjects. Two separate boxes (one for male names and other for females names) contained the paper chits having names written on it and were well shuffled. Two unrelated persons withdrew 10 chits from each boxes (thus 20 male chits and 20 female chits), and whose names appeared on the chits were recruited in the study.

\section{Procedure}

Eligible candidates underwent consent taking. Descriptive variables of all subjects such as gender, age, height, BMI (body-mass index) were assessed at baseline (table 1).

All subjects received the explanation and the familiarization trials of the testing procedures. A gap of two days (to avoid the fatigue due to familiarization trials) was kept between the familiarization session and the pretest data recording session. Participants were instructed not to change their training schedule or activity level acutely during the period of whole study. 


\section{Variables}

Core stability performance was measured using battery of test consisting of Sorensen test, prone plank test, side plank test (right and left), abdominal fatigue test and Sahrmann's core stability test (using stabilizer Pressure biofeedback unit). The static balance testing was done using Stork balance test on both of the lower extremities RSB- right stork balance test; LSB- left stork balance test). The entire performance recording was done at single session only.

Modified Beiring Sorensen Test (Alexis 2006; Bliss \& Teeple 2005; Darin \& Marry 2004; Jacqueline et al 2006; Mcgill et al 1999). Tests the endurance capacity of posterior spinal musculature. The subject was positioned in prone lying position with pelvis at edge of the treatment table with the pelvis and legs well stabilized either manually. Initially the subjects supported their upper extremity on stool/bench in front of table until they were instructed to cross their arm and assume a horizontal position which is to be maintained as long as possible. Total time (in seconds ) for which he/she was able to maintain horizontal position (i.e. the time between the assumption of the horizontal position up to the moment when they lost the horizontal position), was manually recorded using digital stopwatch up to two decimal places. It was registered as posterior core muscles holding capacity.

Prone plank test It selectively tests spinal extensor stabilizer's ability against flexion moment and has good test-retest ability (Schellenber et al 2007) Subjects from the prone lying positions were required to maintain the whole body weight on the forearm and toes while lifting all intermediate segments off the plinth. The maximum duration for which they could maintain the position was the performance of the test (Mcgill SM 2001).

Side plank test The test consisted of subject in side lying position on the firm mattress, with legs extended. Subjects were instructed to support themselves lifting their hips off the mat to maintain a straight line over their full body length and supported themselves on the elbow and their feet The uninvolved arm was held across the chest or simply rested on the lateral thigh of the upper extremity. The duration for which they could maintain the full straight position was the performance of test (Mcgill et al 1999).

Abdominal fatigue test It was performed as per the method of Mcgill et al (1999). It measures the endurance of the anterior abdominal wall by asking the person to hold a situp position as long as they can. The subjects were required to sit on the test bench $t$ and place the upper trunk against a support with an angle of 600 from the test bench. Both knee and hip were flexed to 900 . Both arms were folded across the chest with the hands placed on the opposite shoulder and toes were stabilized to the bed (either by manual support or by straps). The subjects were asked to maintain the body position while the supporting back support was withdrawn. The stopwatch was started at the moment, when the support was withdrawn. The stopwatch stopped when the upper body fell below the
600 position. Time duration between these two points was recorded as the endurance holding score of the anterior abdominal muscle group (Mcgill et al 1999)

Sharman's core stability test (PBU test) It is objective and clinically feasible method to evaluate core stability in the laboratory settings which uses a stabilizer Pressure Biofeedback Unit (PBU) (Chattanooga Group, Inc., Hixson, $\mathrm{TN}$ ) with its inflatable pad placed in the natural lordotic curve, while the subject is lying supine, and is inflated to certain pressure $\mathrm{mm} \mathrm{Hg}$. Subject is required to maintain a fix pressure on the pressure dial of PBU while performing sequentially progressive drills with increasing rotational stresses on the lumbo-pelvic junction. It consists of testing at five progressive levels well described in previous literatures. (Stanton et al 2004; Akhuta \& Nadler 2004; Herrington \& Davies 2005, Mills et al 2005). Its reliability and validity was documented by Mindy et al (2000).

Stork balance test (Gladwell \& Samantha 2006; Hatzitaki et al 2002):- this is used to measure static balance performance as subject is required to assume a single leg standing position on the testing limb and then commanded to raise his/her heel and maintain the balance on the ball of toes of foot for the maximum possible duration (Gladwell \& Samantha 2006). The time duration between the assumption of the position and the loosing of the stable position was taken as the score of the Stork balance test. In its measurement three trials are given for each leg and the time of the longest balance for each leg is recorded (Gladwell \& Samantha 2006).

\section{Data Analysis:-}

Data analysis was done using SPSS (version 15, Predictive Analytics Soft-Ware) and MS-excel (version 2007) software system. Correlation between core endurance tests and stork balance tests was done using Pearson correlation test while that of the PBU test with balance tests was done using Spearman correlation test.

\section{RESULTS}

Demographic data of subjects including age, height, weight were descriptively summarized (table 1 ).

Table 2 indicates that the static balance performance of right lower extremity was significantly correlated with that of the Sorensen test $(\mathrm{r}=0.342, \mathrm{p}=0.03)$, Prone plank test $(\mathrm{r}=0.306, \mathrm{p}=0.05)$ and PBU test $(\mathrm{r}=0.38, \mathrm{p}=0.02)$. Also the similar type of relation was found between left lower extremity static balance performance and the Sorensen Test $(\mathrm{r}=0.306, \mathrm{p}=0.05)$, Prone plank $(\mathrm{r}=0.307, \mathrm{p}=0.05)$ and PBU test $(\mathrm{r}=0.379, \mathrm{p}=0.02)$.

Table 2 also shows that the static balance of left lower extremity performance was not found to be significantly related with right plank test $(r=0.03, p=0.86)$, left plank test $(\mathrm{r}=0.244, \mathrm{p}=0.13)$ and Abdominal fatigue test $(r=0.178, p=0.273)$. Similarly static balance of right lower extremity performance was not found to be significantly related with right plank test $(\mathrm{r}=0.02, \mathrm{p}=0.89)$, left plank test $(\mathrm{r}=0.197, \mathrm{p}=0.22)$ and Abdominal fatigue test $(\mathrm{r}=0.05$, 
$\mathrm{p}=0.73)$.

This pattern of correlation reveals that the static balance performance is significantly correlated with the performance of the Sorensen test, prone plank test and PBU test. The static balance performance does not correlate with Abdominal fatigue test and side plank tests (right and left side plank tests).

\section{T able1: Descriptive statistics of participants}

\begin{tabular}{ll} 
Characteristics & Mean \pm SD $(\mathbf{n = 4 0})$ \\
\hline Gender & $20 \mathrm{M}+20 \mathrm{~F}$ \\
Age $(\mathrm{yrs})$ & $24.24 \pm 1.374$ \\
Weight $(\mathrm{kg})$ & $65.25 \pm 9.35$ \\
Height $(\mathrm{cm})$ & $168 \pm 3.16$ \\
Type of sport & $12 \mathrm{~T}, 8 \mathrm{C}, 12 \mathrm{FB}, 8 \mathrm{BB}$ \\
(usually played by them) &
\end{tabular}

Keys:- C-cricket, BB- basketball, T- tennis, FB-football, M-male, F- female; yrs- years; cm- centimeter; kg-kilogram of the intersegment motion of spine and thus a better control of the body's COG. Gladwell and Samantha (2006) found that the LBA patients have reduced proprioceptive abilities, and when the core stability is enhanced, the low back pain diminishes and the lower extremity proprioception improves. Higher core stability performance might lead to more efficient neural recruitment patterns, increased nerous system actiation, improved synchronization of motor units and a lowering of neural inhibitory reflexes (Ludmila et al, 2003; Staron et al 1994). This possibly explains the need to explore the quantitative correlation between core stability performance and the static balance performance.

During Sorensen test the large trunk postural muscles work along with local stabilizers \& hip extensors to prevent the spine from buckling down. Hip extensors too contribute to the performance of the test varyingly from non significant to strong (Chad EM, 2001; Kankaanpaa et al, 1998). During this test the multifidus demonstrates high EMG activity and is responsible for counteraction of

Table 2: The Pearson correlation values and Spearman coefficient $(n=40)$ between tests of core stability and Stork balance tests.

\begin{tabular}{lllllll}
\hline Variables & Sorensen & $\mathbf{P P}$ & $\mathbf{R P}$ & $\mathbf{L P}$ & $\mathbf{A F}$ & PBU \\
\hline LSB & $=0.306$ & $\mathrm{p}=0.05^{*}$ & $\mathrm{r}=0.307$ & $\mathrm{p}=0.05^{*}$ & $\mathrm{r}=0.029$ & Rho $=0.421$ \\
& $\mathrm{p}=0.86$ & $\mathrm{r}=0.244$ & $\mathrm{p}=0.13$ & $\mathrm{r}=0.178$ & $\mathrm{p}=0.273$ & $\mathrm{P}=0.007^{*}$ \\
RSB & $\mathrm{r}=0.342$ & $\mathrm{p}=0.03^{*}$ & $\mathrm{r}=0.306$ & $\mathrm{p}=0.05^{*}$ & $\mathrm{r}=0.022$ & $\mathrm{Rho}=0.379$ \\
& $\mathrm{p}=0.89$ & $\mathrm{r}=0.197$ & $\mathrm{p}=0.22$ & $\mathrm{r}=0.056$ & $\mathrm{p}=0.733$ & $\mathrm{P}=0.02^{*}$
\end{tabular}

Keys:- *p<0.05; **p<0.001; LSB- left feet stork balance test; RSB- left feet stork balance test; PBU- pressure biofeedback unit test; PP- prone plank test; RP- right plank test; LP left side plank test; AF- abdominal fatigue test; $\mathrm{p}=$ significant level; rho= Spearman coefficient value; $r=$ Pearson correlation coefficient.

\section{DISCUSSION}

The primary aim of the present study was to evaluate the relationship between performance of core stability and the lower extremity static balance performance. Results indicates that static balance performance of right as well as left lower extremity was significantly correlated with that of the Sorensen test, PP (prone plank) test and PBU test. The static balance performance of either extremity was not found to be significantly correlated with RP (right plank), LP (left side plank) and AF (abdominal fatigue test) performance. The different tests used for core stability evaluation in this study, evaluate the different muscles components of core stabilization.

During Stork balance test there is need to stabilize the whole body weight, in balanced fashion, on the ball of toes. It is well known that position of the spine significantly determines the position of the body's COG (center of gravity) and the compensatory muscle synergy/ strategy to counteract the perturbations, to maintain the body's equilibrium state \& to regulate body's postural control. Higher core stability performance allows optimal and long sustained contraction of deeper spinal stabilizer muscles. These stabilizer muscles due to their close proximity with the spine are responsible for better control forces in the sagital plane. Performance of this test is the combined coordination of the local stabilizers, large global muscles of spine $\&$ hip, thus provides effective control of spine's position in sagital plane and better control of COG. This possibly explains higher correlation between Stork balance performance and Sorensen test because the higher coordination of these trunk muscles will be responsible to control the spinal segment controls while stabilizing the body weight on the ball of toes (during Stork balance test).

Prone bridge (prone plank) selectively recruits anterior trunk muscles like external oblique (EO) and lateral stabilizers (Schellenber et al, 2007). This controls the spine in sagital plane thus possibly influences the stork balance test performance.

Side plank or "side bridge" exercise drill challenges quadratus lumborum (Mcgill SM, 2001) which acts as an important lateral stabilizer of the lumbar spine. Present study found no significant correlation among the performance of side plank tests and static balance tests. The possible reason for this may be that the Stork balance test performance depends on the spinal segments and COG control in the sagital plane therefore not significantly influenced by the muscle which have primary stabilizing 
action in the lateral direction (like those of side bridge). The reason of the non-significant correlation between lower extremity balance and the abdominal fatigue could be that during the abdominal fatigue test there is an important role played by global abdominal muscles (rectus abdominus and external oblique muscles) too. At the time of activation of these large global muscles the performance of deep sited smaller core muscles gets masked thus possibly the performance of abdominal fatigue test is not influenced significantly by the activation of core muscles. Though one previous study (Anoop et al 2010) found a significant improvement in the abdominal fatigue test performance after the Core stability training of 6 weeks, yet they attributed this improvement to one specific drill (Seated medicine ball rotation) which they had used in their training regime.

\section{CONCLUSION}

This study concludes that there is significant correlation of the lower extremity balance performance with that of the core stability in sagital plane. This relationship shows that in order to assess and rehabilitate the injured recreationally active player, the core stability enhancement could provide additive advantage.

\section{ACKNOWLEDGMENT}

The author wishes to thank all subjects who kindly participated in this research. This project was supported by a grant devoted to author by Iranian Ministry of education and Medical sciences.

\section{REFERENCES}

- Akuhota V, Nadler SF. (2004) Core strengthening. Archives of Physical Medicine \& Rehabilitation 85 (1): s86-s92

- Alexis O, Sharon O, Charles LL. (2006) Core stability for the female athlete: a review. Journal of Women's Health Physical Therapy 30(2): 11-17.

- Anne P. Balance abilities of workers in physically demanding jobs: with special reference to firefighters of different ages. Journal of sport science \& medicine 2005; 4(8): 1-46.

- Anoop Aggarwal, Kalpana Zutshi, Jitender Munjal, Suraj Kumar, Vijai Sharma. Comparing stabilization training with balance training in recreationally active individuals. International Journal of Therapy and Rehabilitation 2010; 17(5): $245-253$

- Bliss LS, Teeple P. (2005) Core stability: the centerpiece of any training program. Current Sports Medicine Reports. 4: 179-183.

- Bohdanna TZ, Timothy EW, Reeves NP. Effect of Core proprioception on knee injury. American Journal of Sports Medicine 2007; 35(3); 368-373.

- Chad E M. Isometric back extension endurance tests: a review of the literature. Journal of Manipulative and Physiological Therapeutics 2001; 24(2): 110-122.

- Darin TL, Mary LIB. Core stability measures as risk factors for lower extremity injury in athletes. Medicine \& Science in Sports \& Exercise 2004: 926-934.

- David AK, James WY, John HH, Smith J. Abdominal muscle performance as measured by the double leg-lowering test. Archives of Physical Medicine and Rehabilitation 2005; 86(4): 1345-1348

- Gladwell V, Samantha H. Does a program of pilates improves chronic non-specific low back pain? New Zealand Journal of Sports Rehabilitation 2006; 15:338-350.

- Haapasalo H, Parkkart J, Kannus P, Natri A. Knee injuries in leisure time physical activities: a prospective one year follow-up of a finish population cohort. International Journal of Sports Medicine 2007; 28: 72-77.

- Hatzitaki V, Zisi V, Kollias I. Perceptual motor contributions to static and dynamic balance control in children. Journal of Motor Behavior 2002; 34(2): 161-170

- Herrington L \& Davies R. The influence of pilates training on the ability to contract the transverse abdominis muscle in asymptomatic individuals. Journal Of Bodywork And Movement Therapies 2005; 9: 52-57

- Hodges PW, Richardson CA. Contraction of the abdominal muscles associated with movement of the lower limb. Physical Therapy 1997; 77:132-144

- Jacqueline MC, William CB, Shari GM, Michelle LB, Brown LE. The effect of stability ball training on spinal stability in sedentary individuals. Journal of Strength and Conditioning Research 2006; 20(2): 429-435.

- Kankaanpaa M, Taimela SL, Hanninen O. Back and hip extensor fatigability in chronic low back pain patients and controls. Archives of Physical Medicine and Rehabilitation 1998; 79: 412-417.

- Konard P, Schmitz K, Denner A. Neuromuscular evaluation of trunk training exercises. Journal of Athletic Training 2001; 36(2): 109-118.

- Ludmila MC, Reynolds KL, Winter C, Vincent P, Jones MT. effects of physioball and conventional floor exercises on early phase adaptations in back and abdominal core stability and balance in women. Journal of Strength \& Conditioning Research 2003; 17(4): 721-725.

- Mcgill SM, Childs A, Leibenson C. Endurance times for low back stabilization exercises: clinical targets for testing and training from a normal database. Archives of Physical Medicine Rehabilitation 1999; 80: 941-944

- Mcgill SM. Low back stability: from formal description to issues for performance and rehabilitation. Exercise and sports 
sciences reviews 2001; 29(1): 26-31.

- Mcguine TA, Keene JS. The effect of a balance training program on the risk of ankle sprains in high school athletes. American Journal Of Sports Medicine 2006; 34(7):11031111.

- Mills JD, Taunton JE, Mills WA. The effect of a 10-week training regimen on lumbo-pelvic stability and athletic performance in female athletes: A randomized-controlled trial. Physical Therapy in Sport 2005; 6:6066.

- Mindy CC, Harrison K, Wright C. Pressure biofeedback: a useful tool in the quantification of abdominal muscular dysfunction? Physiotherapy 2000; 86(3):127-138.

- Patrick OM, Carl GM. Interventions for the prevention of first time and recurrent ankle sprains. Clinics in Sports Medicine 2008; 27(3): 432-436.

- Richardson JG, Toppenburg R, Commerford. Towards a measurement of active muscle control for lumbar stabilization. Australian Journal of Physiotherapy 1993; 39: 187-193.

- Schellenber, Kerri L, Michael JL, Chan KM, Burnham RS. A clinical tool for office assessment of lumbar spine stabilization endurance: prone \& supine maneuvers. American Journal Of Physical Medicine Rehabilitation 2007; 86(5): 380-386.

- Stanton R, Peter RR, Brendan Humphries, the effect of short-term Swiss ball training on core stability and running economy. Journal of Strength and Conditioning Research 2004; 18(3): 522528

- Staron RS, Karapondo DL, Kraemer WJ, Fry AC, Gordon SE, Falkel JE, Hagerman FE, and Hikida RS. Skeletal muscle adaptations during the early phase of heavy-resistance training in men and women. Journal of applied physiology 1994; 76:1247-1255.

- Timothy AM, Greene JJ. Balance as a predictor of ankle injuries in high school basket players. Clinical Journal of Sport Medicine 2000; 10: 239-244.

- Tropp H, Odenrick P, Sandlund B, Oo kvist LM: Stabilometry for studying postural control and compensation in vertigo of central and beripheral origin. Electromyogr Clin Neurophysiol 1985; 27: 77- 82.

- Willardson JM. Core stability training for healthy athletes: a different paradigm for fitness professionals. National Strength And Conditioning Association 2007; 29(6):42-49.

- Willson JD, Christopher PD, Davis IM. Core stability and its relationship to lower extremity function and injury. Journal of American Academy of Orthopaedic Surgeon 2005; 13:316-325.

- Winter DA: A.B.C. (Anatomy, Biomechanics and Control) of Balance during Standing and Walking, Waterloo, Ontario: Waterloo Press, 1995. 